\title{
Le site du SHE (www.inrp.fr/she)
}

\section{(2) OpenEdition}

12 Journals

Édition électronique

URL : https://journals.openedition.org/histoire-education/1070

DOI : 10.4000/histoire-education. 1070

ISSN : 2102-5452

\section{Éditeur}

ENS Éditions

\section{Édition imprimée}

Date de publication : 1 janvier 2005

Pagination : 71

ISBN : 2-7342-1006-1

ISSN : 0221-6280

Référence électronique

"Le site du SHE (www.inrp.fr/she) », Histoire de l'éducation [En ligne], 105 | 2005, mis en ligne le 23 mars 2009, consulté le 20 mai 2021. URL : http://journals.openedition.org/histoire-education/1070 ; DOI : https://doi.org/10.4000/histoire-education.1070

Ce document a été généré automatiquement le 20 mai 2021.

(c) Tous droits réservés 


\section{Le site du SHE (www.inrp.fr/she)}

1 La mise en ligne de la Bibliographie d'histoire de l'éducation française sous la forme d'une base de données commencera, dans la deuxième moitié de l'année 2005, par une première tranche de trois années $(1998,1999,2000$, correspondant aux bibliographie publiées dans les numéros de septembre 2001, 2002 et 2003 d'Histoire de l'éducation). À terme, cette base de données doit couvrir l'ensemble de la bibliographie, depuis son origine (1979) jusqu'à la dernière année dépouillée, et permettre un référencement plus rapide des publications. Cet outil, qui offrira des possibilités étendues et une grande facilité de recherche, complètera l'ensemble des services relatifs à la revue qui sont déjà accessibles sur le site : information générale; tables rétrospectives des articles, comptes rendus d'ouvrages, actualité scientifique et bibliographies; contenu des numéros récents et à venir ; téléchargement de bons de commande et d'abonnement.

2 Plus généralement, le site du SHE poursuit son développement. Il a fait l'objet, au cours de l'année 2004, de 1300000 connexions, soit plus du triple de l'année précédente. Parmi les nouvelles ressources offertes sur le site, on signalera qu'en complément des bases de données Emmanuelle (répertoire des manuels scolaires depuis la Révolution) et Emmanuelle 5 (bibliographie française sur l'histoire des manuels scolaires), une bibliographie internationale sur le même sujet est désormais disponible (fichier PDF à télécharger). Par ailleurs, les ressources documentaires publiées en ligne dans le cadre du programme de recherches sur le cours magistral se sont enrichies. Un millier de cours manuscrits conservés dans les bibliothèques publiques sont désormais recensés dans la base de données qui leur est consacrée. Enfin, d'importants instruments de recherche font l'objet d'un travail préparatoire à leur mise en ligne, notamment le répertoire de la presse pédagogique publiée depuis le XVIIIe siècle, et un répertoire inédit des établissements privés de la région parisienne (XVIIIe siècle-1940). 